\title{
Insomnia treatment acceptability and preferences of male Iraq and Afghanistan combat Veterans and their healthcare providers
}

\author{
Dana R. Epstein, PhD, RN; ${ }^{1-2^{*}}$ Judith L. Babcock-Parziale, PhD; ${ }^{3}$ Patricia L. Haynes, PhD; ${ }^{3-4}$ Christine A. \\ Herb, MC, RN ${ }^{1}$ \\ ${ }^{1}$ Phoenix Department of Veterans Affairs (VA) Health Care System, Phoenix, AZ; ${ }^{2}$ Arizona State University, Phoenix, \\ AZ; ${ }^{3}$ Southern Arizona VA Healthcare System, Tucson, AZ; ${ }^{4}$ University of Arizona, Tucson, AZ
}

\begin{abstract}
Sleep difficulty is a prevalent problem among returning Veterans. Although there is strong evidence for the efficacy and durability of cognitive-behavioral treatment for insomnia (CBT-I) in the general population, the interventions require motivation, attention, and adherence from patients to achieve successful outcomes. Given the unique characteristics of Operation Iraqi Freedom/Operation Enduring Freedom (OIF/OEF) Veterans who have experienced blast-related injuries and other trauma, CBT-I for these patients may require modification, including alternative delivery methods, to ensure effective implementation and positive outcomes. We interviewed 18 OIF/OEF Veterans who screened positive for mild traumatic brain injury and 19 healthcare providers to determine the acceptability of insomnia treatments and preferences for the interventions and treatment delivery. Veterans and providers had distinct preferences for insomnia treatment and its delivery. The treatments the Veterans found most acceptable were also the ones they preferred: relaxation treatment and pharmacotherapy. The providers identified relaxation therapy as the most acceptable treatment. Veterans preferred the individual treatment format as well as electronic methods of treatment delivery. Despite some differences between patients and providers, a compromise through modification of empirically supported behavioral treatments is feasible, and implications for preference-based insomnia intervention development and testing are discussed.
\end{abstract}

Key words: cognitive-behavioral treatment, healthcare providers, insomnia, OIF/OEF Veterans, pharmacotherapy, polytrauma, sleep, traumatic brain injury, treatment acceptability, treatment preference.

\section{INTRODUCTION}

Sleep disturbance is one of the most frequently cited symptoms among soldiers returning from the Iraq war [1]. Physiological, psychological, military, and civilian readjustment stressors can initiate insomnia in Operations Iraqi Freedom/Operation Enduring Freedom (OIF/ OEF) Veterans. In response to acute sleep problems, patients may develop ineffective strategies to obtain sleep, poor sleep habits, and sleep-related dysfunctional cognitions. These responses perpetuate sleep difficulty and lead to chronic insomnia [2].

Abbreviations: BDI-II = Beck Depression Inventory-II, CBT = cognitive-behavioral treatment, CBT-I = CBT for insomnia, DSM-IV = Diagnostic and Statistical Manual of Mental Disorder-Fourth Edition, ISI = Insomnia Severity Index, OIF/OEF = Operation Iraqi Freedom/Operation Enduring Freedom, PCL$\mathrm{M}=$ Posttraumatic Stress Disorder Checklist-Military, PDA = personal digital assistant, PTSD = posttraumatic stress disorder, QUERI = Quality Enhancement Research Initiative, TAP = Treatment Acceptability and Preferences, TBI = traumatic brain injury, VA = Department of Veterans Affairs.

*Address all correspondence to Dana R. Epstein, PhD, RN; Phoenix VA Health Care System, 650 E Indian School Rd (RS/151), Phoenix, AZ 85012; 602-277-5551, ext 17725; fax: 602-212-2047. Email: dana.epstein@va.gov

http://dx.doi.org/10.1682/JRRD.2011.06.0114 
Insomnia is highly prevalent in patients with traumatic brain injury (TBI) [3], the leading injury in the current combat theaters of operation, and may be more common in mild than moderate or severe injuries [4]. Insomnia symptoms are reported by 50 percent of TBI patients, and 29 percent meet diagnostic criteria for an insomnia syndrome [3]. TBI patients report that insomnia interferes with daily functioning and exacerbates symptoms such as cognitive deficits, irritability, pain, and fatigue [3]. Difficulty with sleep onset and maintenance was reported by 93.5 percent of OIF/OEF Veterans seen at a Department of Veterans Affairs (VA) Polytrauma Network Site [5]. Sleep impairment is common in disorders associated with polytrauma such as posttraumatic stress disorder (PTSD) [6], depression [7], and pain [8]. These disorders are highly comorbid with TBI and may be better predictors of sleep disturbance than mild TBI $[5,9]$. In an analysis of the "polytrauma triad" (PTSD, pain, and TBI), PTSD was the major contributor to sleep difficulty in Veterans, and when it occurred with TBI, sleep disturbance increased [5]. Given the prevalence and effect of insomnia in mild TBI and polytrauma patients, tailored insomnia interventions are needed for this unique Veteran population.

In 2005, a National Institutes of Health State-of-theScience panel recognized cognitive-behavioral treatment (CBT) as a first-line therapy for insomnia [10]. Two single-case design studies used CBT for insomnia (CBT-I) for mild-to-severe TBI patients in the non-Veteran population [11-12]. Cognitive deficits did not limit the subjects' ability to understand the treatment rationale, to self-monitor sleep, to demonstrate insight, or to benefit from CBT-I. Significant statistical and clinical reductions in insomnia, night-to-night variability, and fatigue were found and intervention effects were maintained at 1 and 3 months posttreatment. CBT-I improved sleep in conditions associated with traumatic injuries such as depression [13] and pain [14] in the non-Veteran population and PTSD in Veterans, including the OIF/OEF cohort [15]. These findings suggest that OIF/OEF Veterans who have experienced traumatic injuries may benefit from CBT-I. Unfortunately, nothing is known about this Veteran cohort's views on the acceptability of and preference for insomnia treatments.

Acceptability represents a favorable attitude toward a treatment option based on careful consideration of the treatment attributes (e.g., appropriateness, suitability, effectiveness, risks, and convenience). Patients' percep- tions of treatment attributes influence their preferences for treatment. Treatment preferences denote patients' choices of treatment, that is, the treatment option patients want to receive to manage the presenting clinical problem [16]. Eliciting patient preferences is a key element of patient-centered care [17]. An increasing number of studies involve assessing participants' perception of treatment preferences, yet there is limited knowledge of patients' views regarding acceptability of and preferences for insomnia treatments [16].

Two studies found that behavioral interventions for insomnia were more acceptable and suitable than pharmacological treatment [18-19]. Morin et al. found the short-term effects of behavioral and medication treatments were rated equivalently by participants, but participants thought nonpharmacological treatment would be more effective in the long term, have fewer side effects, and have a more beneficial effect on daytime functioning than pharmacotherapy [18]. Vincent and Lionberg replicated Morin et al.'s findings in younger participants with poorer sleep efficiency and greater psychopathology [19]. Although the available evidence indicates that persons with insomnia in the non-Veteran population rate behavioral interventions more favorably than pharmacological treatment, there is limited knowledge of preferences for specific behavioral interventions and treatment delivery characteristics such as setting and dosage. This type of knowledge is important when tailoring interventions to fit special populations, such as OIF/OEF Veterans.

Adapting current treatment approaches for the new Veteran cohort requires patient and provider perspectives. VA healthcare providers believe the characteristics of returning Veterans, such as age, technology competence, and complex health problems, necessitate modification and development of interventions that appeal to this cohort [20]. Providers find younger Veterans' preferences differ from older cohorts and modify clinical treatment accordingly [20]. Healthcare providers' feedback regarding Veterans' likes and dislikes about treatment in general, and insomnia intervention in particular, can provide information that may not be obtained through Veteran interviews alone. In order to develop and test insomnia interventions suited to the unique characteristics of Veterans who have experienced single or multiple traumatic events and/or injuries, this study determined the acceptability of insomnia treatments and preferences for the interventions and treatment delivery characteristics among the Veterans and their healthcare providers. 


\section{METHODS}

\section{Design}

A descriptive design was used for the 6-month pilot study. Data were obtained from the Veterans and providers at a single time point for the purpose of describing insomnia treatment acceptability and preferences.

\section{Settings and Subjects}

Preferences for treatment were obtained from OIF/ OEF Veterans and providers. Veterans were referred to the study by the Polytrauma Support Clinic and Polytrauma Network Site teams at two VA medical centers. Veterans referred to the study (1) had experienced single or multiple traumatic events and/or injuries (i.e., blast or improvised explosive device, grenade or land mine, vehicular accident, fragment or bullet wound above the shoulders, or fall) and possibly had a remote TBI event, (2) complained of sleep difficulty, and (3) were interested in participation. During the study screening, the research staff determined the Veteran's eligibility based on a complaint of sleep onset and/or sleep maintenance and insomnia difficulty of at least 1-month duration with sleep-related daytime impairment such as problems with mood, performance, relationships, work, or fatigue. Professionals at both VA sites who provide healthcare for OIF/OEF Veterans in primary care, mental health clinics, and through the Polytrauma Support Clinic and Polytrauma Network Site teams were invited to participate in the study.

\section{Variables and Measures}

Demographic, military service, and clinical characteristics were assessed with standard questions. Current use of sleep medication was determined through the Veteran's electronic health record and verified by the Veteran to ensure inclusion of medication prescribed outside of the VA. Insomnia severity, depression, and PTSD measures were used to describe the cohort of Veterans enrolled in this pilot project.

\section{Treatment Acceptability and Preferences}

The Treatment Acceptability and Preferences (TAP) instrument has established psychometric properties [16] and assesses treatment acceptability and preferences through descriptions of evidence-based treatment options for insomnia. Behavioral treatment options included sleep education and hygiene, stimulus control therapy, sleep restriction therapy, relaxation therapy, and mindfulness training based on recent findings [21]. Sleep education and hygiene are composed of lifestyle recommendations that promote sleep, as well as basic information about sleep, sleep architecture, developmental changes in sleep, and other factors [22]. Sleep education and hygiene were included because they are fundamental components of insomnia treatment, albeit with limited efficacy [23-24]. Although sleep education and hygiene are typically part of CBT-I approaches, we wanted the Veterans to have the opportunity to express their level of preference for it as a single treatment in order to inform future intervention development. In stimulus control therapy, a set of instructions is used to strengthen the bed and bedroom as cues for sleepiness and sleep and weaken them as signals for wakefulness [22]. Sleep restriction therapy uses an individualized sleep-wake schedule to consolidate sleep by limiting the amount of time in bed to the amount of total sleep time the patient reports, typically obtained through daily sleep diaries [25]. Relaxation therapy reduces cognitive and somatic arousal through techniques such as diaphragmatic breathing, progressive muscle relaxation, and guided imagery [22]. Mindfulness training for insomnia increases moment-to-moment awareness of the somatic and mental states associated with insomnia and how to use awareness to manage emotional reactions to insomnia and its daytime consequences [26]. The pharmacological treatment option included a broad description of pharmacotherapy for sleep, a well-established treatment modality for insomnia.

The treatment option description introduced the name of the treatment and its purpose and explained the nature of the activities comprising it and its usual dose, mode of delivery, effectiveness, and risks or side effects. The Figure illustrates the description information for one of the treatment options, sleep restriction therapy (also referred to as sleep efficiency therapy), presented in the TAP instrument. No information was provided that compared any aspect of a treatment to that of another treatment. Following the description was a set of seven items to rate the treatment option on a 5-point rating scale ranging from "not at all" (0) to "very much" (4) in terms of acceptability. Acceptability included the treatment's suitability for insomnia, short- and long-term effectiveness in managing insomnia, effectiveness in improving daily functioning, severity of side effects/risks, ease of use, and the degree to which the Veterans would be willing to comply with the treatment. Using the seven items, a total acceptability score (possible range 0-28) was computed 


\section{Treatment Name: Sleep efficiency therapy}

Description: In sleep efficiency therapy, you learn to develop a sleep schedule that is based on the amount of time you are actually sleeping. You will learn when to go to bed, when to wake up, and the total amount of time that you can spend in bed. The sleep schedule is determined by the insomnia therapist and you. Each week, the schedule changes as you start to increase the amount of time you sleep and your sleep becomes regular. This treatment requires that you follow the instructions carefully and practice them at home where your sleep problems occur. Daily sleep diaries are filled out every morning when you wake up so you and the insomnia therapist can monitor your sleep and changes in your sleep. It takes a few minutes to fill out the diary.

How the Treatment is Given: The treatment is given weekly over a 4 to 8 week period using weekly individual appointments or weekly class (group) sessions.

Effectiveness: Sleep efficiency therapy is effective for the short and long-term treatment of insomnia.

Risks and Side Effects: Patients may feel more tired at the beginning of treatment, but this usually decreases after a few weeks.

Figure.

Description of a treatment option.

to represent overall treatment acceptability. Following the acceptability ratings, participants were requested to state whether or not they had a preference for any of the treatment options they rated and, if they did, to indicate which was the most preferred. The third section of the instrument inquired about treatment characteristics such as delivery modalities, duration, and frequency. Providers answered similar questions from their perspective. Openended questions related to insomnia treatment were also included in patient and provider versions.

\section{Insomnia Severity Index}

The Insomnia Severity Index (ISI) is a seven-item self-report instrument that captures a person's perception of insomnia using a Likert-type response format [27]. The ISI items partially address the diagnostic criteria for insomnia in the Diagnostic and Statistical Manual of Mental Disorders-Fourth Edition (DSM-IV) [28]. In addition to the degree and type of insomnia problem, the consequences of insomnia and the level of worry or distress caused by insomnia are assessed. The patient is asked to think about his or her sleep over the past 2 weeks. A higher score indicates more severe insomnia. The ISI has established psychometric properties across the adult lifespan in the non-Veteran population $[27,29]$ with four severity categories: absence of insomnia (0-7), subthreshold insomnia (8-14), moderate insomnia (15-21), and severe insomnia (22-28) [27]. Preliminary internal consistency reliability (Cronbach alpha) was 0.90 in 121 OIF/OEF Veterans [30].

\section{Beck Depression Inventory-II}

The Beck Depression Inventory-II (BDI-II) is a 21item self-report instrument that measures the presence and severity of the symptoms of depression using a Likert-type response format [31]. The symptoms correspond to those listed in the DSM-IV [28]. The patient is asked to think about how he or she has felt over the past 2 weeks. Higher BDI-II scores indicate higher levels of depression. The instrument has established psychometric properties and cut-off scores for severity of depression: 0-13 = minimal depression, 14-19 = mild depression, 20-28 = moderate depression, and 29-63 = severe depression 
[32-33]. The BDI-II scores were gathered from the Veteran's health record at one study site.

\section{Posttraumatic Stress Disorder Checklist-Military}

The PTSD Checklist-Military (PCL-M) is a brief self-report 17-item screening instrument that measures PTSD symptoms and the degree to which the Veteran is bothered by the symptoms [34]. The PCL-M is used in research and clinical settings and has established psychometric properties across many populations, including combat Veterans [34]. A higher cut-off score (i.e., 60) was reported for a sample of Veterans who had experienced multiple potentially traumatic events [34].

\section{Procedure}

A protocol manual was used that included scripts and checklists for the staff and interviewers to follow during screening and for each step of the research visit. Eligible Veterans participated in a 60 min interview with a research staff member (i.e., Master's or doctoral level nurse or a clinical psychologist). During the meeting, the participant completed the demographic, military service, and clinical characteristics questionnaire; ISI; and PCL$M$. The Veterans were told that the purpose of the TAP questionnaire was to obtain Veterans' views and insights about different insomnia treatment options in order to develop and test interventions to meet their needs and lifestyle. The Veterans were asked to read and rate each option or the interviewer could read it, if desired. All of the participants read the options and completed the ratings themselves. The responses to the open-ended question about additional information that would help the Veteran with his insomnia problem were completed by the interviewer in order to follow-up on Veterans' statements. The providers received a parallel version of the TAP questionnaire via medical center mail.

\section{Data Analysis}

Descriptive analyses were used to address the specific aim. Summary measures, including means, standard deviations for continuous variables, and frequency distributions for binary variables, are reported. Treatment acceptability differences between Veterans and providers were examined using independent $t$-tests. In addition to the quantitative data, open-ended questions followed each treatment rating section on the TAP. The responses to the open-ended questions were employed to determine themes, assist in interpretation of the acceptability and preference ratings, and develop recommendations for the modification and testing of future insomnia treatments.

\section{RESULTS}

\section{Characteristics of Veteran Sample}

Twenty-seven Veterans were referred to the study. Four were not interested in participation, three did not show up for the appointment, and two had a work conflict. Table 1 provides the demographic and clinical characteristics of the participating Veterans. The 18 participating male Veterans ranged in age from 22 to 48 years. Approximately 39 percent of the Veterans had two or three deployments. The median time from the Veterans' most recent deployment to the time of the study participation was 13 months (interquartile range 9-40 mo). Over one-third of the Veterans were Hispanic. Most of the Veterans' traumatic events and/or injuries were related to explosive devices. The participants' selfreported average insomnia duration was just over 2 years, with a median duration of 36 months (interquartile range 9-50 mo). All participating Veterans complained of difficulty with both initiating and maintaining sleep. Fatigue, irritability, and daytime sleepiness were the most commonly reported sleep-related daytime problems. The Veterans' mean ISI scores were in the moderate to severe insomnia range [27]. The Veterans' mean depression scores indicated a moderate level of depression [33]. All participants' PCL-M scores were greater than the VA primary care screening cut-off for PTSD, and 83 percent of the Veterans had a score higher than the VA PTSD specialty mental health clinic screening cut-off [35]. From the electronic health record, we determined that 17 Veterans had positive VA TBI Clinical Reminders, and 1 Veteran had a prior diagnosis of TBI.

\section{Characteristics of Provider Sample}

Of the 23 questionnaires sent to providers, 19 were returned. Thirty-three percent of providers were psychologists. Equal numbers of registered nurses (staff nurses), nurse practitioners, and occupational therapists completed the instrument (17\% each). Additionally, two providers were speech language pathologists and one was a recreational therapist. 
Table 1.

Demographic and clinical characteristics of Veterans $(n=18)$.

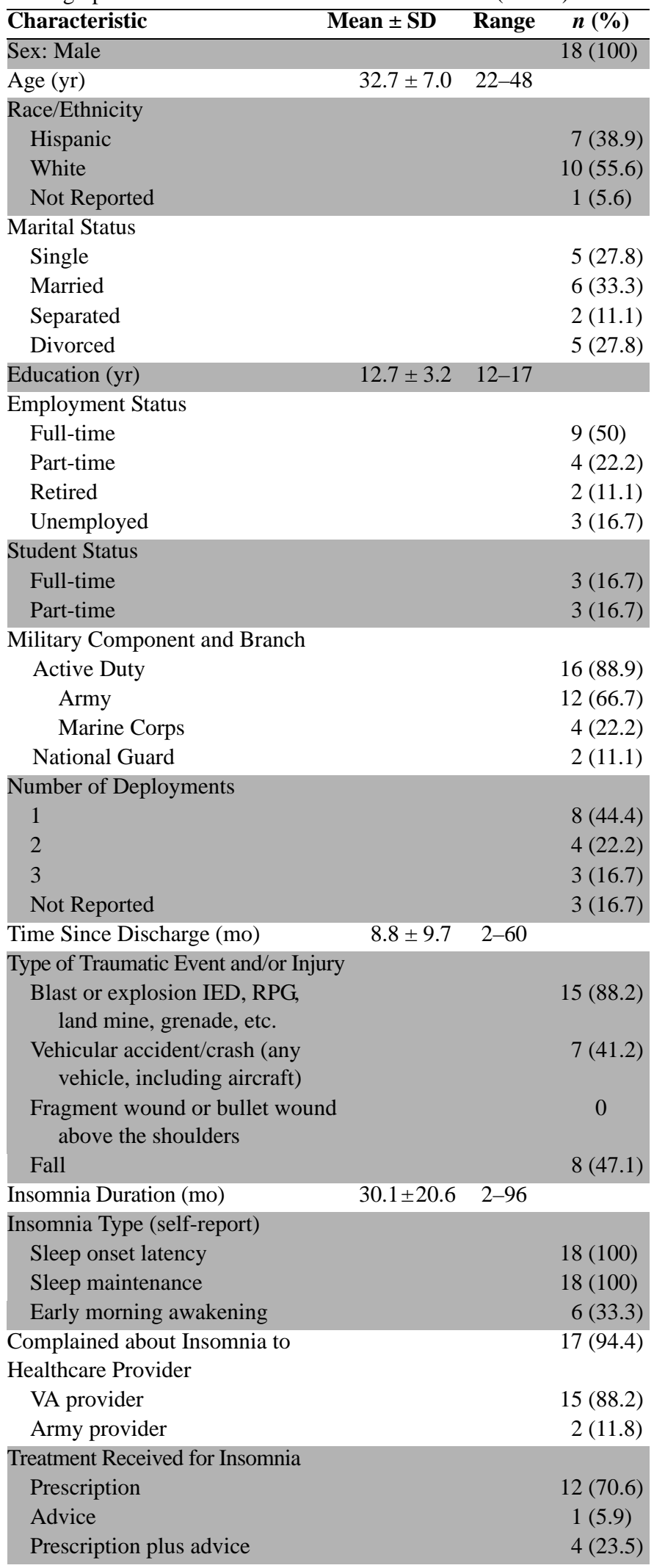

Table 1. (cont)

Demographic and clinical characteristics of Veterans $(n=18)$.

\begin{tabular}{|c|c|c|}
\hline Characteristic & Mean \pm SD & $n(\%)$ \\
\hline Current Use of Sleep Medication & & $10(55.6)$ \\
\hline Prescription & & $9(90.0)$ \\
\hline Over-the-counter & & $1(10.0)$ \\
\hline
\end{tabular}

Psychological Distress/Daytime Impairment

Related to Sleep Difficulty

Fatigue/malaise

$17(94.4)$

Irritability/mood

16 (88.9)

Daytime sleepiness

$16(88.9)$

Concerns/worries about sleep 14 (77.8)

Motivation/energy/activity 14 (77.8)

Tension/headaches/GI symptoms 13 (72.2)

Relationships

Possible errors driving/work

$11(61.1)$

Work/school performance

$10(55.6)$

Insomnia Severity Index

$9(50.0)$

Beck Depression Inventory-II $\quad 26.9 \pm 9.9$
$\quad(n=9)$

Posttraumatic Stress Disorder $\quad 62.1 \pm 14.0 \quad 28-79$

Checklist-Military

$\overline{\mathrm{GI}}$ = gastrointestinal, $\mathrm{IED}$ = improvised explosive device, $\mathrm{RPG}$ = rocket propelled grenade, $\mathrm{SD}=$ standard deviation. $\mathrm{VA}=$ Department of Veterans Affairs.

\section{Treatment Acceptability and Preferences}

Veterans and providers differed significantly on one treatment acceptability item: stimulus control therapy. The providers found the treatment more acceptable. Veterans found relaxation therapy and pharmacotherapy to be the most acceptable and most preferred treatments for insomnia (Tables 2 and 3). Veterans considered pharmacotherapy as a "quick fix" that fit their demanding schedules. Despite the preference given to pharmacotherapy, Veterans expressed their concerns about dependency and a desire to stop its use. The Veterans' written responses included suggestions for combined treatments (behavioral

\section{Table 2.}

Treatment acceptability ratings (mean \pm standard deviation) by Veterans $(n=18)$ and healthcare providers $(n=19)$.

\begin{tabular}{|c|c|c|}
\hline Treatment Type & Veterans & Providers \\
\hline Relaxation Therapy & $13.8 \pm 5.5$ & $15.2 \pm 2.9$ \\
\hline Pharmacotherapy & $13.0 \pm 5.3$ & $12.7 \pm 2.6$ \\
\hline $\begin{array}{l}\text { Sleep Hygiene and } \\
\text { Education }\end{array}$ & $11.3 \pm 3.3$ & $13.0 \pm 4.7$ \\
\hline Sleep Restriction Therapy & $10.5 \pm 5.1$ & $11.1 \pm 3.6$ \\
\hline Stimulus Control Therapy ${ }^{*}$ & $10.3 \pm 5.0$ & $13.4 \pm 2.8$ \\
\hline Mindfulness Strategies & $9.6 \pm 5.6$ & $9.7 \pm 3.6$ \\
\hline
\end{tabular}


Table 3.

Insomnia treatment preferences of Veterans $(n=18)$.

\begin{tabular}{lc}
\hline Treatment Type & \% \\
\hline Relaxation Therapy & 72.2 \\
Pharmacotherapy & 56.0 \\
Mindfulness Strategies & 50.0 \\
Sleep Restriction Therapy & 44.4 \\
Sleep Hygiene and Education & 44.4 \\
Stimulus Control Therapy & 38.9 \\
\hline \hline
\end{tabular}

and medication) and the use of sleep medication early in treatment with the goal of discontinuation. The intermittent use of medications was suggested by some Veterans as an alternative to nightly use. Mindfulness strategies were more preferred than the behavior therapies, yet received the lowest acceptability rating. Comments were focused on preferences for "easy" treatments that fit with Veterans' busy lives. Nightmares were frequently mentioned as a problem that causes awakenings and prevents return to sleep.

The providers rated relaxation, stimulus control instructions, and sleep education and hygiene as the most acceptable treatments. Pharmacotherapy received a higher acceptability rating than sleep restriction therapy and mindfulness training. Providers' comments indicated that medications have the potential for dependency and may be viewed by Veterans as "an easy fix," which the Veterans also mentioned. The providers' written comments regarding stimulus control instructions and sleep restriction indicated that it might be difficult for the Veterans to comply because of problems with attention, concentration, and follow-through. They also thought that the sleepiness sometimes associated with sleep restriction might exacerbate cognitive symptoms. Providers thought mindfulness training would be a difficult skill for the Veterans to master. Motivation to practice the treatments could be a barrier, and Veterans might look for an "easy answer," such as medication.

The Veterans preferred the individual treatment format and electronic methods of treatment delivery (Table 4). Many Veterans commented that they do not like groups, as was reflected in the quantitative data. Sixtyone percent wanted insomnia treatment that lasted less than 5 weeks, and the majority (95\%) did not want a treatment session that lasted over an hour.

Similar to the Veterans' ratings, the individual treatment delivery format was most preferred by the providers (Table 5). The providers' favored DVDs and personal digital assistants (PDAs) as the next most preferred deliv-
Table 4.

Veterans' delivery preferences $(n=18)$.

\begin{tabular}{lc}
\hline Treatment Delivery Format & $\mathbf{\%}$ \\
\hline Individual & 72.2 \\
Internet & 72.2 \\
DVD & 66.7 \\
PDA & 61.1 \\
MP3 files & 55.6 \\
Booklets & 50.0 \\
Telephone & 38.9 \\
Audiotape & 38.9 \\
Group/Class & 16.7 \\
\hline PDA = personal digital assistant.
\end{tabular}

Table 5.

Healthcare providers' delivery preferences $(n=19)$.

\begin{tabular}{lc}
\hline Treatment Delivery Format & $\mathbf{\%}$ \\
\hline Individual & 89.5 \\
DVD & 63.2 \\
PDA & 63.2 \\
Group/Class & 47.4 \\
Internet & 47.4 \\
MP3 files & 42.1 \\
Booklets & 42.1 \\
Telephone & 36.8 \\
Audiotape & 26.3 \\
\hline PDA = personal digital assistant.
\end{tabular}

ery methods. The providers' comments indicated electronic methods should be supplemented by therapist contact to provide a "hands on" approach for comprehension and application. Daily sleep diaries used to monitor sleep were thought to be a good idea, but some raised concerns whether Veterans' would be able to adhere to the daily recording. The providers thought cognitive difficulties common to OIF/OEF Veterans who have experienced blast or other injuries could affect adherence to measurement and treatment and ultimately affect outcomes. Flexible, easily implemented treatment approaches were favored, but caution was raised to avoid inducing any extra fatigue in this population to prevent exacerbation of existing cognitive deficits. Similar to Veterans' views, providers thought nightmares were a significant issue and an integral part of addressing sleep disturbance.

\section{DISCUSSION}

The OIF/OEF Veterans interviewed expressed distinct preferences for type of insomnia treatment and delivery 
method. The treatments the Veterans found most acceptable were also the ones they preferred: relaxation treatment and pharmacotherapy. Relaxation may appeal to this Veteran cohort because of the high levels of reported anxiety and stress [36]. Many insomniacs are aroused and anxious; therefore, relaxation-based techniques can serve two purposes. First, insomniacs can relax and fall asleep more easily, and second, they can incorporate the skills they learn into their everyday lives to cope with stressful situations [37]. The generalization of the skill set to daily stressful situations could be advantageous since this Veteran cohort has numerous physical and mental health problems and difficulty with reintegration [38], which are associated with anxiety and stress. Based on the Veterans' and providers' preference and its established treatment efficacy, relaxation may be an appropriate insomnia intervention to test in this population.

Although pharmacotherapy was rated as an acceptable and preferred treatment for insomnia (over one-half of participants used sleep medication), Veterans indicated that pharmacotherapy is not a desired long-term treatment. Intermittent use of medication, use of medication early in treatment, and combined treatments were recommended by Veterans. Intermittent use of medication and its appropriate application to chronic insomnia remain unanswered research questions [39]. The use of hypnotics early in treatment for acute insomnia may be beneficial because of their rapid effect and the potential to avoid the development of perpetuating behavioral and cognitive factors that lead to a chronic insomnia problem [39]. Unfortunately, many returning Veterans already have an established, chronic insomnia problem when they are seen for postdeployment healthcare. Clinical indications and best methods for implementing a combined approach have not been clearly defined [39]. A recent study suggested that the sequential approach of initial CBT plus medication (zolpidem) followed by discontinuation of medication with the extension of CBT may reduce drug exposure and dependency as well as allow time to integrate psychological and behavioral strategies [40]. The addition of medication added some benefit for increasing total sleep time. For OIF/OEF Veterans, many of whom tend to be short sleepers [41], the additional advantage of increased sleep time from a combined treatment approach may be particularly useful. Future research testing sequential and combined approaches may benefit OIF/OEF Veterans. Future insomnia treatment preference assessment could be improved by specifying different types of sleep medication, in a manner similar to the specification of behavioral treatments in the TAP.

Healthcare providers found stimulus control therapy more acceptable than did the Veterans. Aspects of stimulus control are often well known to clinicians in the general sense of "stay out of bed if you cannot sleep." For Veterans, the description of stimulus control included ". . . help you get rid of activities that interfere with sleep (such as watching TV in bed)," which may be treatment elements patients think they would resist. Sleep restriction therapy was one of the least acceptable treatments to the providers. They felt sleep restriction therapy would be difficult to implement because of short sleep durations in the Veterans, problems adhering to an imposed sleepwake schedule, and the resultant fatigue that could affect already impaired cognitive functioning. The comment regarding fatigue is particularly relevant since fatigue is a common problem among Iraq war Veterans [1]. In the current study, fatigue was rated as the most impairing daytime consequence related to insomnia. Sleep restriction was also a less acceptable option for Veterans. Short sleep duration was recently reported among military personnel, particularly those with combat exposure [41]. The description, which included “. . . develop a sleep schedule based on the amount of time you are actually sleeping,” may have contributed to the Veterans' low acceptability rating. About half of the Veterans preferred mindfulness approaches, yet providers rated them as least acceptable and had concerns about their use (e.g., "need to break entrenched self-concepts," "requires introspection”). It may be feasible to test some components of mindfulness training, such as the body scan and breathing awareness, with other nonpharmacological treatments and/or short-term pharmacotherapy.

Veterans expressed specific preferences for treatment delivery methods. Veterans preferred treatment that lasts less than 5 weeks. CBT-I typically involves about six sessions [24]. A dose-response study found one and four sessions produced the most favorable short-term subjective and objective sleep outcomes [42]. Abbreviated versions of CBT-I have received testing [43-47], and a brief treatment model is supported by findings that OIF/OEF Veterans have low treatment attendance and high dropout rates [48]. Veterans preferred the use of an individual treatment format and electronic methods to deliver insomnia treatment, specifically the Internet. Returning Veterans are technology savvy; 97 percent have Internet 
access and 70 percent use it daily [38]. In order to accommodate combat Veterans' preferences, providers incorporate technology into patients' clinical treatment, e.g., through the use of PDAs [20]. A recent study by Ritterband et al. in the non-Veteran population that used the Internet to deliver multicomponent insomnia treatment over a 9-week period showed significant improvement in sleep outcomes [49]. One dilemma with self-help methods for insomnia, such as the Internet, is whether the users know that the treatment is correct for the sleep problem they are experiencing [22]. Patients with other sleep disorders may present symptoms similar to insomnia. If an insomnia self-help treatment is selected, appropriate treatment may be delayed and safety concerns arise. The Ritterband et al. study addressed these issues through restricting entry to the Internet program and a careful screening process, including a personal interview [49]. The complex health problems of returning Veterans would warrant a similar approach, including therapist contact, if self-help electronic methods were tested.

A common thread in Veterans' and providers' comments regarding sleep was nightmares and the effect on sleep maintenance. Several studies have used behavioral and pharmacological therapy for sleep disturbance and nightmares in Veterans [15,50-53]. Future studies testing insomnia and nightmare treatment in OIF/OEF combat Veterans are warranted. Determination of the optimal sequencing of insomnia and nightmare interventions is needed, as well as their sequencing with the evidencebased PTSD treatments offered in VA mental health clinics. This is particularly important in light of data showing that insomnia is a residual symptom following successful CBT for PTSD including remission of nightmares and hypervigilance [54].

\section{CONCLUSIONS}

While OIF/OEF Veterans and providers had definite preferences for treatment and its delivery, a compromise through modification of empirically supported treatments is certainly possible. This might include testing brief behavior therapy, combined and sequential short-term pharmacotherapy and behavioral approaches, and alternative delivery methods. Knowledge of this cohort's insomnia treatment preferences can increase clinicians' awareness of and willingness to explain treatment options and allow Veterans to participate in decisionmak- ing about treatment choices. Therefore, it will be important to determine in a future study if treatment options are explained and Veterans are able to begin insomnia treatment with their preferred evidence-based intervention, whether Veterans are more adherent and less likely to drop out of treatment. If the preferred intervention is not effective, knowledge that additional treatment options are available may increase the likelihood that the Veteran will talk to the provider and explore other treatment possibilities.

A recurring concern expressed by OIF/OEF Veterans was that their busy schedules could make it difficult to follow the insomnia treatment recommendations described in the TAP instrument. An initial test of a preference-based treatment should therefore include a feasibility study to determine attendance, attrition, adherence, frequency and duration of intervention use, and participant evaluation and feedback. The challenge is to develop preference-based insomnia treatments that fit with the Veterans' complex health problems and the difficult reintegration issues involving social, family, and work relationships.

\section{ACKNOWLEDGMENTS}

\section{Author Contributions:}

Study concept and design: D. R. Epstein, J. L. Babcock-Parziale. Acquisition of data and statistical analysis: D. R. Epstein,

J. L. Babcock-Parziale, P. L. Haynes, C. A. Herb.

Analysis and interpretation of data: D. R. Epstein, J. L. Babcock-Parziale, P. L. Haynes, C. A. Herb.

Critical revision of manuscript for important intellectual content:

D. R. Epstein, J. L. Babcock-Parziale, P. L. Haynes.

Study supervision: D. R. Epstein, J. L. Babcock-Parziale.

Financial Disclosures: The authors have declared that no competing interests exist.

Funding/Support: This material was based on work supported by the VA Health Services Research and Development's Quality Enhancement Research Initiative (QUERI) (grant RRP 07-309).

Additional Contributions: The authors thank Daniela Lopez and Valerie Scheller for assisting with data collection and entry. The authors gratefully acknowledge the Veterans and providers who participated in the study. The authors thank the VA Polytrauma and Blast-Related Injury QUERI for its support.

Institutional Review: The study was approved by the site-specific institutional review boards (Phoenix VA Health Care System and Southern Arizona VA Healthcare System). All VA requirements for research involving human participants were met. Veterans who were interested and eligible to enroll completed the informed consent process. Participant Follow-Up: The authors do not plan to inform participants of the publication of this study. 


\section{REFERENCES}

1. Hoge CW, Terhakopian A, Castro CA, Messer SC, Engel CC. Association of posttraumatic stress disorder with somatic symptoms, health care visits, and absenteeism among Iraq war veterans. Am J Psychiatry. 2007;164(1):150-53. [PMID:17202557] http://dx.doi.org/10.1176/appi.ajp.164.1.150

2. Spielman AJ, Caruso LS, Glovinsky PB. A behavioral perspective on insomnia treatment. Psychiatr Clin North Am. 1987;10(4):541-53.[PMID:3332317]

3. Ouellet M-C, Beaulieu-Bonneau S, Morin CM. Insomnia in patients with traumatic brain injury: frequency, characteristics, and risk factors. J Head Trauma Rehabil. 2006;21(3): 199-212. [PMID:16717498] http://dx.doi.org/10.1097/00001199-200605000-00001

4. Ouellet MC, Savard J, Morin CM. Insomnia following traumatic brain injury: a review. Neurorehabil Neural Repair. 2004;18(4):187-98. [PMID:15669131] http://dx.doi.org/10.1177/1545968304271405

5. Lew HL, Pogoda TK, Hsu P-T, Cohen S, Amick MM, Baker E, Meterko M, Vanderploeg RD. Impact of the "polytrauma clinical triad" on sleep disturbance in a Department of Veterans Affairs outpatient rehabilitation setting. Am J Phys Med Rehabil. 2010;89(6):437-45. [PMID:20489391] http://dx.doi.org/10.1097/PHM.0b013e3181ddd301

6. Spoormaker VI, Montgomery P. Disturbed sleep in posttraumatic stress disorder: secondary symptom or core feature? Sleep Med Rev. 2008;12(3):169-84. [PMID:18424196] http://dx.doi.org/10.1016/j.smrv.2007.08.008

7. Buysse DJ, Angst J, Gamma A, Ajdacic V, Eich D, Rössler W. Prevalence, course, and comorbidity of insomnia and depression in young adults. Sleep. 2008;31(4):473-80. [PMID:18457234]

8. Moldofsky H. Sleep and pain. Sleep Med Rev. 2001; 5(5):385-96. [PMID:12531004] http://dx.doi.org/10.1053/smrv.2001.0179

9. Hoge CW, McGurk D, Thomas JL, Cox AL, Engel CC, Castro CA. Mild traumatic brain injury in U.S. Soldiers returning from Iraq. N Engl J Med. 2008;358(5):453-63. [PMID:18234750] http://dx.doi.org/10.1056/NEJMoa072972

10. National Institutes of Health. National Institutes of Health state of the science conference statement of manifestations and management of chronic insomnia in adults, June 1315, 2005. Sleep. 2005;28(9):1049-57. [PMID:16268373]

11. Ouellet M-C, Morin CM. Cognitive behavioral therapy for insomnia associated with traumatic brain injury: a singlecase study. Arch Phys Med Rehabil. 2004;85(8):1298-1302. [PMID:15295756] http://dx.doi.org/10.1016/j.apmr.2003.11.036
12. Ouellet MC, Morin CM. Efficacy of cognitive-behavioral therapy for insomnia associated with traumatic brain injury: a single-case experimental design. Arch Phys Med Rehabil. 2007;88(12):1581-92. [PMID:18047872] http://dx.doi.org/10.1016/j.apmr.2007.09.006

13. Manber R, Edinger JD, Gress JL, San Pedro-Salcedo MG, Kuo TF, Kalista T. Cognitive behavioral therapy for insomnia enhances depression outcome in patients with comorbid major depressive disorder and insomnia. Sleep. 2008; 31(4):489-95. [PMID:18457236]

14. Jungquist CR, O'Brien C, Matteson-Rusby S, Smith MT, Pigeon WR, Xia Y, Lu N, Perlis ML. The efficacy of cognitive-behavioral therapy for insomnia in patients with chronic pain. Sleep Med. 2010;11(3):302-9. [PMID:20133188] http://dx.doi.org/10.1016/j.sleep.2009.05.018

15. Ulmer CS, Edinger JD, Calhoun PS. A multi-component cognitive-behavioral intervention for sleep disturbance in veterans with PTSD: a pilot study. J Clin Sleep Med. 2011; 7(1):57-68. [PMID:21344046]

16. Sidani S, Epstein DR, Bootzin RR, Moritz P, Miranda J. Assessment of preferences for treatment: validation of a measure. Res Nurs Health. 2009;32(4):419-31.

[PMID:19434647] http://dx.doi.org/10.1002/nur.20329

17. Sidani S, Epstein D, Miranda J. Eliciting patient treatment preferences: A strategy to integrate evidence-based and patient-centered care. Worldviews Evid Based Nurs. 2006; 3(3):116-23. [PMID:16965313] http://dx.doi.org/10.1111/j.1741-6787.2006.00060.x

18. Morin CM, Gaulier B, Barry T, Kowatch RA. Patients' acceptance of psychological and pharmacological therapies for insomnia. Sleep. 1992;15(4):302-5. [PMID:1519003]

19. Vincent N, Lionberg C. Treatment preference and patient satisfaction in chronic insomnia. Sleep. 2001;24(4):411-17. [PMID:11403525]

20. Friedemann-Sánchez G, Sayer NA, Pickett T. Provider perspectives on rehabilitation of patients with polytrauma. Arch Phys Med Rehabil. 2008;89(1):171-78. [PMID:18164350] http://dx.doi.org/10.1016/j.apmr.2007.10.017

21. Ong JC, Shapiro SL, Manber R. Combining mindfulness meditation with cognitive-behavior therapy for insomnia: a treatment-development study. Behav Ther. 2008;39(2):171-82. [PMID:18502250] http://dx.doi.org/10.1016/j.beth.2007.07.002

22. Bootzin RR, Epstein DR. Understanding and treating insomnia. Annu Rev Clin Psychol. 2011;7(1):435-58. [PMID:17716026] http://dx.doi.org/10.1146/annurev.clinpsy.3.022806.091516 
23. Morin CM, Culbert JP, Schwartz SM. Nonpharmacological interventions for insomnia: a meta-analysis of treatment efficacy. Am J Psychiatry. 1994;151(8):1172-80. [PMID:8037252]

24. Morin CM, Bootzin RR, Buysse DJ, Edinger JD, Espie CA, Lichstein KL. Psychological and behavioral treatment of insomnia: update of the recent evidence (1998-2004). Sleep. 2006;29(11):1398-1414. [PMID:17162986]

25. Spielman AJ, Yang CM, Glovinsky PB. Insomnia: sleep restriction therapy. In: Sateia MJ, Buysee DJ, editors. Insomnia: diagnosis and treatment. London (UK): Informa Healthcare; 2010. p. 277-89.

26. Ong J, Sholtes D. A mindfulness-based approach to the treatment of insomnia. J Clin Psychol. 2010;66(11):1175-84. [PMID:20853441] http://dx.doi.org/10.1002/jclp.20736

27. Bastien CH, Vallières A, Morin CM. Validation of the Insomnia Severity Index as an outcome measure for insomnia research. Sleep Med. 2001;2(4):297-307.

[PMID:11438246] http://dx.doi.org/10.1016/S1389-9457(00)00065-4

28. American Psychiatric Association. Diagnostic and statistical manual of mental disorders: DSM-IV, 4th ed. Washington (DC): American Psychiatric Association; 1994.

29. Smith S, Trinder J. Detecting insomnia: comparison of four self-report measures of sleep in a young adult population. J Sleep Res. 2001;10(3):229-35. [PMID:11696076] http://dx.doi.org/10.1046/j.1365-2869.2001.00262.x

30. Epstein DR, Goren K, Bushnell ML. Preliminary evaluation of the Insomnia Severity Index in Operation Enduring Freedom/Operation Iraqi Freedom veterans. Sleep. 2009; 32:0831.

31. Beck AT, Steer RA, Ball R, Ranieri W. Comparison of Beck Depression Inventories-IA and -II in psychiatric outpatients. J Pers Assess. 1996;67(3):588-97. [PMID:8991972] http://dx.doi.org/10.1207/s15327752jpa6703_13

32. Arnau RC, Meagher MW, Norris MP, Bramson R. Psychometric evaluation of the Beck Depression Inventory-II with primary care medical patients. Health Psychol. 2001;20(2): 112-19. [PMID:11315728]

http://dx.doi.org/10.1037/0278-6133.20.2.112

33. Beck AT, Steer RA, Brown GK. Manual for the Beck Depression Inventory-II. San Antonio (TX): Psychological Corp; 1996.

34. Keen SM, Kutter CJ, Niles BL, Krinsley KE. Psychometric properties of PTSD Checklist in sample of male veterans. J Rehabil Res Dev. 2008;45(3):465-74. [PMID:18629754] http://dx.doi.org/10.1682/JRRD.2007.09.0138

35. National Center for PTSD. PTSD Checklist (PCL) [Internet]. Washington (DC): Department of Veterans Affairs;2007 [updated 2011 Dec 23]. Available from: http://www.ptsd.va.gov/professional/pages/assessments/ ptsd-checklist.asp

36. Hoge CW, Castro CA, Messer SC, McGurk D, Cotting DI, Koffman RL. Combat duty in Iraq and Afghanistan, mental health problems, and barriers to care. N Engl J Med. 2004; 351(1):13-22. [PMID:15229303] http://dx.doi.org/10.1056/NEJMoa040603

37. Bootzin RR, Nicassio PO. Behavioral treatments for insomnia. Prog Behav Modif. 1978;6:1-45.

38. Sayer NA, Noorbaloochi S, Frazier P, Carlson K, Gravely A, Murdoch M. Reintegration problems and treatment interests among Iraq and Afghanistan combat veterans receiving VA medical care. Psychiatr Serv. 2010;61(6): 589-97. [PMID:20513682] http://dx.doi.org/10.1176/appi.ps.61.6.589

39. Morin CM. Combined therapeutics for insomnia: should our first approach be behavioral or pharmacological? Sleep Med. 2006;7(S1, Suppl 1):S15-19. [PMID:16702028] http://dx.doi.org/10.1016/j.sleep.2006.03.005

40. Morin CM, Vallières A, Guay B, Ivers H, Savard J, Mérette C, Bastien C, Baillargeon L. Cognitive behavioral therapy, singly and combined with medication, for persistent insomnia: a randomized controlled trial. JAMA. 2009;301(19): 2005-15. [PMID:19454639]

http://dx.doi.org/10.1001/jama.2009.682

41. Seelig AD, Jacobson IG, Smith B, Hooper TI, Boyko EJ, Gackstetter GD, Gehrman P, Macera CA, Smith TC; Millennium Cohort Study Team. Sleep patterns before, during, and after deployment to Iraq and Afghanistan. Sleep. 2010; 33(12):1615-22. [PMID:21120123]

42. Edinger JD, Wohlgemuth WK, Radtke RA, Coffman CJ, Carney CE. Dose-response effects of cognitive-behavioral insomnia therapy: a randomized clinical trial. Sleep. 2007;30(2):203-12.[PMID:17326546]

43. Edinger JD, Sampson WS. A primary care "friendly" cognitive behavioral insomnia therapy. Sleep. 2003;26(2):177-82. [PMID:12683477]

44. Carter PA. A brief behavioral sleep intervention for family caregivers of persons with cancer. Cancer Nurs. 2006; 29(2):95-103. [PMID:16565618] http://dx.doi.org/10.1097/00002820-200603000-00003

45. McCrae CS, McGovern R, Lukefahr R, Stripling AM. Research evaluating brief behavioral sleep treatments for rural elderly (RESTORE): A preliminary examination of effectiveness. Am J Geriatr Psychiatry. 2007;15(11):979-82. [PMID:17974868]

http://dx.doi.org/10.1097/JGP.0b013e31813547e6

46. Goodie JL, Isler WC, Hunter C, Peterson AL. Using behavioral health consultants to treat insomnia in primary care: a clinical case series. J Clin Psychol. 2009;65(3):294-304. [PMID:19152339] http://dx.doi.org/10.1002/jclp.20548 
47. Buysse DJ, Germain A, Moul DE, Franzen PL, Brar LK, Fletcher ME, Begley A, Houck PR, Mazumdar S, Reynolds CF 3rd, Monk TH. Efficacy of brief behavioral treatment for chronic insomnia in older adults. Arch Intern Med. 2011;171(10):887-95. [PMID:21263078] http://dx.doi.org/10.1001/archinternmed.2010.535

48. Erbes CR, Curry KT, Leskela J. Treatment presentation and adherence of Iraq/Afghanistan era veterans in outpatient care for posttraumatic stress disorder. Psychol Serv. 2009; 6(3):175-83. http://dx.doi.org/10.1037/a0016662

49. Ritterband LM, Thorndike FP, Gonder-Frederick LA, Magee JC, Bailey ET, Saylor DK, Morin CM. Efficacy of an Internet-based behavioral intervention for adults with insomnia. Arch Gen Psychiatry. 2009;66(7):692-98. [PMID:19581560] http://dx.doi.org/10.1001/archgenpsychiatry.2009.66

50. Raskind MA, Peskind ER, Hoff DJ, Hart KL, Holmes HA, Warren D, Shofer J, O’Connell J, Taylor F, Gross C, Rohde $\mathrm{K}, \mathrm{McF}$ all ME. A parallel group placebo controlled study of prazosin for trauma nightmares and sleep disturbance in combat veterans with post-traumatic stress disorder. Biol Psychiatry. 2007;61(8):928-34. [PMID:17069768] http://dx.doi.org/10.1016/j.biopsych.2006.06.032

51. Cook JM, Harb GC, Gehrman PR, Cary MS, Gamble GM, Forbes D, Ross RJ. Imagery rehearsal for posttraumatic nightmares: a randomized controlled trial. J Trauma Stress. 2010;23(5):553-63. [PMID:20839311] http://dx.doi.org/10.1002/jts.20569

52. Ruff RL, Ruff SS, Wang X-F. Improving sleep: Initial headache treatment in OIF/OEF veterans with blastinduced mild traumatic brain injury. J Rehabil Res Dev.
2009;46(9):1071-84. [PMID:20437313]

http://dx.doi.org/10.1682/JRRD.2009.05.0062

53. Calohan J, Peterson K, Peskind ER, Raskind MA. Prazosin treatment of trauma nightmares and sleep disturbance in soldiers deployed in Iraq. J Trauma Stress. 2010;23(5): 645-48. [PMID:20931662] http://dx.doi.org/10.1002/jts.20570

54. Zayfert C, DeViva JC. Residual insomnia following cognitive behavioral therapy for PTSD. J Trauma Stress. 2004; 17(1):69-73. [PMID:15027796] http://dx.doi.org/10.1023/B:JOTS.0000014679.31799.e7

Submitted for publication June 21, 2011. Accepted in revised form November 10, 2011.

This article and any supplementary material should be cited as follows:

Epstein DR, Babcock-Parziale JL, Haynes PL, Herb CA. Insomnia treatment acceptability and preferences of male Iraq and Afghanistan combat Veterans and their healthcare providers. J Rehabil Res Dev. 2012;49(6):867-78. http://dx.doi.org/10.1682/JRRD.2011.06.0114

ResearcherID: Dana R. Epstein, PhD, RN: E-4916-2012; Patricia L. Haynes, PhD: E-4921-2012

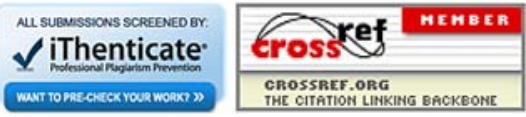

